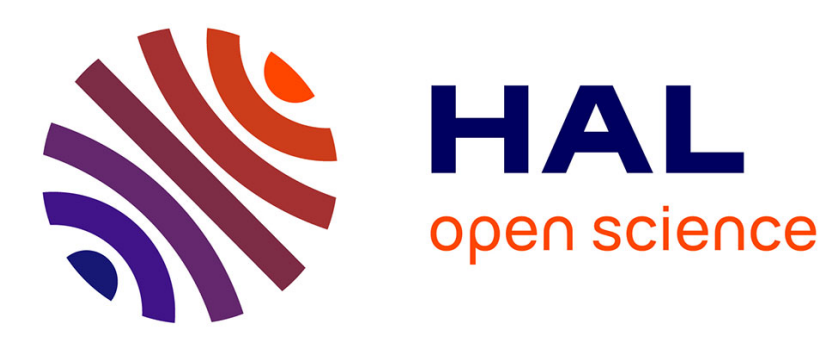

\title{
A Responsive demand management framework for the minimisation of waste in convenience food manufacture
}

\author{
R Darlington, S Rahimifard
}

\section{To cite this version:}

R Darlington, S Rahimifard. A Responsive demand management framework for the minimisation of waste in convenience food manufacture. International Journal of Computer Integrated Manufacturing, 2006, 19 (08), pp.751-761. 10.1080/09511920500501632 . hal-00513368

\section{HAL Id: hal-00513368 \\ https://hal.science/hal-00513368}

Submitted on 1 Sep 2010

HAL is a multi-disciplinary open access archive for the deposit and dissemination of scientific research documents, whether they are published or not. The documents may come from teaching and research institutions in France or abroad, or from public or private research centers.
L'archive ouverte pluridisciplinaire $\mathbf{H A L}$, est destinée au dépôt et à la diffusion de documents scientifiques de niveau recherche, publiés ou non, émanant des établissements d'enseignement et de recherche français ou étrangers, des laboratoires publics ou privés. 


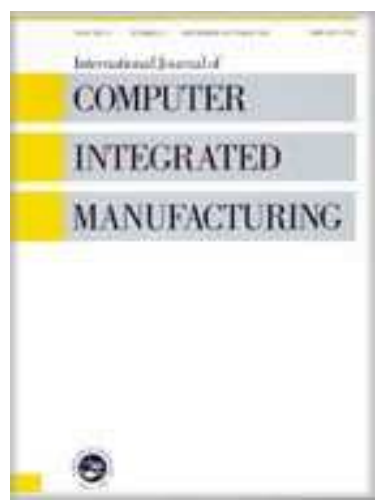

\section{A Responsive demand management framework for the minimisation of waste in convenience food manufacture}

\begin{tabular}{|r|l|}
\hline Journal: & International Journal of Computer Integrated Manufacturing \\
\hline Manuscript ID: & TCIM-2005-IJCIM-0029 \\
\hline Manuscript Type: & Original Manuscript \\
\hline Author: & 27-Sep-2005 \\
\hline Complete List of Authors: & $\begin{array}{l}\text { Darlington, R; Loughborough University, Dept of Manufacturing } \\
\text { Engineering } \\
\text { Rahimifard, S; Loughborough University, Dept of Manufacturing } \\
\text { Engineering }\end{array}$ \\
\hline Keywords: & PRODUCTION PLANNING, SUPPLY CHAIN MANAGEMENT \\
\hline Keywords (user): & Food Manufacture, Waste Minimisation \\
\hline
\end{tabular}

\section{\$ scholarONE" \\ Manuscript Central}




\title{
A Responsive demand management framework for the minimisation of waste in convenience food manufacture
}

\author{
R. DARLINGTON and S. RAHIMIFARD*
}

Centre for Sustainable Manufacturing and Reuse /Recycling Technology (SMART), Wolfson School of Manufacturing and Mechanical Engineering, Loughborough University, UK, LE11 3TU

\begin{abstract}
Convenience food manufacture generates considerable waste through poor planning of production. This problem is particularly acute for products that have a very short shelf life and will be disposed of as waste should their shelf life expire. Chilled ready-meals are convenience foods with relatively short shelf lives and volatile consumer demands; their manufacture is based on forecasted volumes and when demand has been over-predicted, considerable wastes are created. This is referred to as OverProduction Waste which typically sees finished product disposed of through commercial waste channels due to lack of demand. The research reported in this paper has investigated the generation of a responsive demand management framework for the reduction of overproduction wastes.
\end{abstract}

Keywords: Waste Minimisation; Reactive Planning; Food Manufacture

\section{Introduction}

The widely accepted principle behind sustainable development is "to meet the needs of today's generation without jeopardising the ability of future generations being able to provide for themselves". Environmental considerations are of the utmost importance in all aspects of life, and where production and manufacture are concerned it is clear that an environmentally responsible attitude in addition to economic acumen is necessary for businesses to remain profitable and sustainable in the future. One of the issues of environmentally conscious manufacturing is the minimisation of waste during the production stage. In food manufacture a significant proportion of this waste is due to the short shelf life of both the ingredients and products and is often generated as a result of overproduction to meet retailer demands.

Convenience foods provide consumers with value-added products that save preparation time and are available in a range of formats from fresh to frozen snacks, meal accompaniments or even meal solutions. The research reported in this paper focused on chilled ready-meals which typically have a very short shelf life due to their fresh nature and are subject to large volatility in demand, in part due to consumer's tendency to purchase these products on impulse. The retailer's own label branded goods have the prominent market share, with the manufacture of these products usually being outsourced to independent manufacturers, several of whom may be subcontracted to provide the same product, to demanding specifications required by the retailer. In this sector, the retailers often hold significant buying power which influences their relationships with supplier 
manufacturers. In this relationship, the retailers focus on minimising stock holding while fulfilling consumer demand which has led to a situation where late confirmation of order volumes is commonplace. This confirmation of the required volumes shortly before the products must be shipped presents several planning complexities for manufacturers and often results in creation of large amounts of overproduction waste.

One of the major research objectives has been to develop a responsive framework to deal with volatile demands of products in this sector and to minimise the wastes as a result of overproduction based on unreliable forecasted values. The initial sections of the paper provide an overview of relevant research and legislation in this area and a waste model developed for convenience food manufacture. The main sections of the paper outline and illustrate through a case study the various stages within the Responsive Demand Management (RDM) framework which has been generated to minimise OverProduction Waste (OPW).

\section{Review of relevant legislation}

Concern with regard to the environment, and manufacturing's impact upon it, is such that improvement in environmental performance has not been left to the economic incentive of cost savings, but enforced through compliance with legislation. Such coercion has reportedly resulted in more effective means of business performance being adopted (Sarkis 2001; Maxwell 2003). Material wastes created in food supply networks are largely either organic or resultant from packaging processes, with the food industry responsible for using over $50 \%$ of the total packaging output for the UK (Environment agency 2001). The European Union directives on packaging waste (Directive 94/62/EC 1994; Directive 04/12/EC 2004), indicate the measures and targets that member states must implement with each target being periodically reviewed. The UK Packaging Regulations first introduced in 1998 is based upon these directives and require companies handling greater than 50 tonnes of packaging to comply with the legislation and take responsibility for their 'obligation' of packaging waste in order to reduce the environmental impact of such packaging waste. Fernie and Hart (2001) describe how this obligation gave the greater share of the responsibility to Retailers, with manufacturers required to recover only $9 \%$ of packaging. The actual recovery is often undertaken by third party reprocessors through compliance schemes. Other food industry wastes such as material wastes, those arising from processing or waste water and effluent are considered under the Integrated Pollution Prevention and Control (IPPC) directive 96/61/EC (1996), which is to be fully implemented by October 2007. The IPPC measures were created to prevent, or at least reduce emissions to air, land and water from manufacturing activities whereby companies have to demonstrate that reasonable steps to reduce emissions to acceptable levels are being taken.

An integrated Environmental Management System (EMS) has been described as a suitable response to legislation and regulations relating to a companies Environmental performance (Lillford 1997) allowing all activities to be managed and benchmarked against the companies EMS database. A family of International Standards referred to as ISO 14000 provides the framework by which an EMS may be structured (ISO14001) considering auditing, monitoring, analysis and assessment including Life Cycle Assessment (LCA) whereby any potential environmental impacts across a products life are considered. The activity undertaken in an EMS has been compared to that of existing manufacturing management systems, such as Total Quality Management (Borri1995), while acknowledging the continuous improvement basis upon which EMS's are based as they develop with technological and political advancement (Gupta 1994; Borri 1995). 


\section{Waste Model for Convenience Food Supply}

Wastes are created in the food industry often through process inefficiencies, planning complexities, improper use of materials and sometimes simply from not using the ingredients before spoilage. In most cases, food quality degrades with chemical changes and micro-organism growth over the time it is held until the shelf life expires and the food becomes unfit for consumption (Pegg 1999). Shelf life is measured in days for most convenience foods and can be the cause of consumer created wastes; retailer created waste from overstocked shelves; and manufacturer/supplier wastes where both the finished product and their ingredients have not been used in the delivery window. The shelf life demands on the convenience food supply network means that products cannot effectively be made to stock, creating planning difficulties to meet the volatile demand. Wastes in food industry may be generated through any stage of preparation, manufacture, supply or consumption as shown in Figure 1; however the main focus for this research has been the OverProduction Wastes which typically account for the biggest proportion of the manufacturer's wastes constituting as much as $40 \%$ of total cost of wastes.

Several convenience food manufacturers contributed to a series of exploratory interviews used as the basis of the work in creating the waste model. IDEF0 representations (Dorador and Young 2000) have been utilised to model and demonstrate the relationships between each stage and the sources of particular types of waste. The IDEF0 representation for the broad stages of food supply through a products life is shown in figure 2 . The wastes identified across this representation are described in sections $3.1-3.5$.

[Insert figure 1 about here]

[Insert figure 2 about here]

\subsection{Bulk organic wastes}

These wastes are associated with the preparation of ingredients and may include inedible parts of the ingredient, such as stems, leaves, bones, excess animal fat and contaminated materials, such as outer layers of vegetables that are spoiled.

\subsection{Water wastes}

Water is used in large quantities in food processing, predominantly in the preparation and cooking stages of the product's life cycle, as indicated in figure 2. Water may form an ingredient for many products, though it may be a waste described in this context as the water reclaimed at the end of the process either as a carrier for waste and contamination or a biproduct from cooking or processing operations. In addition, water and detergents are the primary method for cleaning machinery and facilities of food deposits and contaminants, and large volumes of fresh clean water are used daily for this process. The Environment Agency (2001) reports that the UK food and drink industry used 6600 Million litres per day in $1997 / 98$ accounting for around 10\% of the non household public water supply and direct abstraction of water by primary industry.

\subsection{Processing wastes}

Processing wastes may be created by a number of different sources, often resultant due to poor processes and housekeeping, process inherent losses or poor conformity. This could 
include spillages, damages and contamination of product caused by poor handling procedures and operator neglect or poor processes, e.g. forming equipment making improper seals on packs etc. The creation of such wastes will largely result in waste product being spilt to the floor which will be disposed of as bulk organic wastes when the equipments and production areas are cleaned. Bi-products in this context are materials that are created by the manufacturing process but have little or no value and cannot be used elsewhere. They may be well anticipated in production such as estimated volumes of juices or animal fats created with product which are removed and disposed of to give the desired product quality or consistency. Wastes may be created at any time for any ingredient or product failing to adequately conform to specifications, with all final products being tested for quality, consistency, appearance, flavour and aroma etc. Rejected products may be final packaged products and be added to standard refuse waste or may be batches of sauces, meat or pasta for example that can be added to bulk organic wastes.

\subsection{Packaging wastes}

Packaging wastes are widespread in the food industry, due to the essential requirements for preventing contamination or spoilage of foods by their immediate environment. Packaging can vary from large paper sacks for ingredients to various plastic bags sheets and pouches depending on the product and packaging requirements. In some cases ingredients are packaged specifically for a processing operation and then have to be removed from that packaging for subsequent processing e.g. vacuum packaging of meats for cooking processes. The material properties and specific nature of the packaging used in each application are considered in conjunction with marketing, logistics issues and environmental concerns (Prendergast and Pitt 1996). Typically packing materials are all disposed of in similar manner to commercial waste disposal.

\subsection{OverProduction Wastes}

OverProduction Wastes constitute significant cost to the company as materials, energy and production capacity in manufacturing are wasted given that the product no-longer has an end customer. OPW may also be used to describe batches of ingredients that have been prepared before order confirmation decreases in volume and cannot be re-used before expiry. In such cases the ingredients will typically be scrapped to commercial waste and sent to landfill as many own label manufacturers cannot re-direct the product to different customers in keeping with their agreements with the retailers. It may be possible to reduce the impact both commercially and environmentally of OPW by the authorised extension of the products shelf life by a companies technical department for those products to be sold at cost prices, for example in the staff shop. Such practices are not always feasible and therefore the authors argue that a more structured route to reducing incidences of OPW must be sought.

When considering where manufacturing wastes are generated we must first establish the manufacturing processes and production steps that must be undertaken to create each product. Ready-meals and convenience foods are varied in their form and format, and as such the processing of each product likewise varies. However, a typical generic process route has been presented in figure 3, and used as the basis for a more detailed waste model, encompassing activities common to most ready-meal products. It should be noted that figure 3 details the activities identified in the manufacturing phase as outlined in figure 2.

[Insert figure 3 about here]

\section{Minimisation of Wastes due to Overproduction}


The Environment Agency and Envirowise (formerly the Environmental Technology Best Practice Programme) in the UK have waste minimisation clubs, projects and guidelines demonstrating the scope for businesses to make substantial cost savings in making environmental improvement activities in their operations. This view of the economic incentive of waste reduction promotes companies to investigate the costs of the wastes they create and thus reduce those costs. The costs of bulk organic wastes as described in the waste model in section 3 are low, the mechanisms by which they are collected being their primary expense, and provided they are disposed of responsibly present little environmental hazard. For the convenience foods considered in this research, volumes of bulk organic waste represented a small proportion of both the costs and volumes of wastes created. However OPW typically constitute over $40 \%$ of the costs of wastes and accounts for at least $20 \%$ and as much as $50 \%$ of the volume of waste.

One of the major reasons for the generation of OPW is that in these applications production volumes are often based on forecasted values as the adoption of a Make-ToOrder approach is not feasible due to the required order lead-times being significantly shorter than the manufacturing lead-time of the product. As mentioned earlier this is often caused by the late confirmation of the required order volumes by the Retailers. This presents a substantial challenge to production planning, where overproduction results in significant waste and to the detriment of the company's profitability. In order to effectively reduce the amounts of OPW and promote greater manufacturing sustainability, the factors influencing and aggravating these planning issues must be identified and carefully considered. The research reported in this paper has identified three main methods of reducing the impact from the impact of long manufacturing lead-time versus short order lead-time:

1. Reduce manufacturing lead-time through improved production processes and technology

2. Increase order lead-times through more effective management of supply chain activities

3. Utilisation of an intelligent reactive production planning approach

Based on these, a framework for Responsive Demand Management (RDM) has been proposed which aims to reduce the Overproduction Waste. This framework utilises a number of contemporary modelling and analysis techniques, such as simulation and Value Stream Mapping, to achieve its objectives. Figure 4 depicts the major goal of the RDM framework which is to minimise the overlap between the manufacturing lead-time and order lead-time (Darlington and Rahimifard 2004).

[Insert figure 4 about here]

In some cases, the reduction of manufacturing lead-time and increase of order leadtime could result in a Make-To-Order approach being feasible (i.e. order lead-time is longer than the manufacturing lead-time). However in most applications the improvement of manufacturing lead-time and order lead-time will still not enable a Make-to-Order approach to be adopted (i.e. the manufacturing lead-time is still longer than the required order leadtime). In these cases, a hybrid production planning approach based on the use of both static and dynamic scheduling rules can be adopted to minimise the overproduction waste as outlined in the remaining sections of this paper.

\subsection{A Responsive Demand Management Framework for convenience food manufacture}


The RDM framework consists of three stages as outlined in figure 5, which are briefly described below and are further discussed and illustrated with the aid of a case study in the remaining sections of this paper.

\section{i. $\quad$ Health Check}

The review and analysis of the effectiveness and efficiencies of the manufacturing activities and associated supply chain processes forms the focus of the health-check to be carried out in the first stage of the RDM framework. Such a health-check aims to benchmark the fitness of both the material and information flows along with the company's environmental performance.

[Insert figure 5 about here]

The subsequent process modelling in this first stage provides a visualisation of the 'current state' of manufacturing and supply chain activities and is based on information collected through the health-check process.

\section{ii. $\quad$ Improvements to Production and Supply Chain Processes}

This stage of the RDM framework examines the various existing production technologies and aims to identify inefficiencies or the use of more up-to-date techniques to reduce the overall required manufacturing lead-times of the product. In addition, analysis of the supply chain activities to identify opportunities for closer integration of information flows and greater availability of consumer demand data to the manufacturers and suppliers is undertaken.

\section{iii. $\quad$ Reactive Production Planning}

The final stage of the RDM framework adopts a hybrid planning method based on static scheduling of standard operations (i.e. operations that are common among many products and do not impart product identification, e.g. cleaning meats, cooking operations) and a realtime approach to the planning of special operations (i.e. operations that provide product identification e.g. adding specific sauce or packaging).

\section{Case Study}

The various stages of the RDM framework have been applied in a convenience food manufacturer which produces a range of fresh ready-meals for one of the major retailers in the UK, under the retailer's own brand. In the case of this particular food manufacturer, the order confirmations from these retailers are received within 24 hours of required delivery times. However the average manufacturing lead times are 36 hours and hence traditionally the production levels in this company has been based on forecasted values. As part of this research, the three stages of the RDM framework have been applied to identify possible improvements in production processes and supply chain activities to be able to adopt a Make-To-Order approach for production planning. In addition the Two Stage Planning approach has been implemented to be able to utilise a real-time planning of special operations, hence minimising the OverProduction Waste. These three stages are described below.

\subsection{Health Check and Process Modelling}

The process of health check for the company was based on completing a questionnaire through a set of interviews with key decision makers and providing feedback which serves to 
highlight the context to the current practices and inefficiencies that are in place. The sources of waste identified for the case study manufacturer were consistent with the stages of production as outlined in figure 3. The current state of manufacturing processes and supply chain activities were recreated utilising Value Stream Mapping (VSM) and based on information from the health check as illustrated in figure 6 (Hines and Rich 1997). In addition a considerable amount of data was not historically recorded by the company and hence had to be collected by means of observation of current production and material handling practices.

[Insert figure 6 about here]

The ability of Value Stream maps to highlight complexities of communication channels, timings, methods and frequency of contact makes them a useful tool to identify the improvements in manufacturing and supply chain activities. The modelling of the information and physical flows related to products between production processes, through to finished goods store and distribution centres, highlighted a number of non-value adding processes. This provided an immediate benefit for the company to focus on a range of improvement initiatives targeted at these non-value adding processes and resulted in the investment by the company to integrate their MRP system with their Electronic Data Interchange used by the retailers.

\subsection{Production and Supply Chain Improvement}

In order to improve the production lead-time within the company a systematic approach based on consideration of the product, processes, resources, and layouts was adopted. A number of contemporary optimisation techniques, as outlined in figure 7 were utilised to analyse and improve the product family groupings, the process set-ups, the range of resources and the layout with which they are positioned in the production system. The company's production system is typified by 'Human Centred Manufacturing System' and this provided the flexibility of utilising processes and personnel on alternative production lines to reduce bottlenecks and delays in manufacturing that contributed to a lengthening of production lead-times.

\section{[Insert figure 7 about here]}

The analysis of production layouts in the company identified a number of potential methods for reduction of production lead-time through re-grouping of product families, processes, and their related resources. These potential optimisation scenarios were subjected to a what-if analysis through development of a simulation model.

The simulation model utilised for this project required a high degree of flexibility to examine a large number of what-if scenarios related to these potential optimisation methods. SIMUL8 simulation software (Simul8 corporation 2001), has been utilised for this simulation project. The straightforward user interface and accessibility of the visual simulator enabled significant number of simulation experiments to be carried out. Figure 8 provides an animation of the simulation model of the company production system, in which nine filling lines were serviced by two elevators, each separately providing meat and sauce components to 9 filling lines. The simulation project was able to provide comparative data relating to ingredient queues due to elevator availability and breakdown with the analysis undertaken offline and without disruption to production.

[Insert figure 8 about here] 
In order to improve the order lead-time within the company a review of Supply Chain practices, data flow and communication streamlining and adopted technology and applications was undertaken. A number of contemporary Supply Chain Management techniques as outlined in figure 9 were utilised to identify potential improvements in supply chain activities with the retailer. This review indicated that the greatest improvement to be obtained by streamlining communication between the company and the retailers. This allows the timely use of consumer demand data, enabling manufacturers to respond more quickly to variability, and adjust production volumes and plans appropriately. One of the most effective techniques for such communication streamlining is based on the adoption of e-commerce technologies which was considered by the company for future development.

[Insert figure 9 about here]

In addition, the case study company took part in a scheme implemented by the retailer in which employees (planners) from ready-meal supplier manufacturers were placed at the retailer head offices to co-ordinate communications and help order placement. This has significantly improved order placement resulting in an increase in reaction time for the manufacturers to fulfil retailer's demands. In addition, the utilisation of high tech IT based tracking processes have been investigated through a two year trial within one of the retailer's distribution centres. The early results from this trial indicated significant improvements can be achieved across supply chain replenishment through increased visibility of product requirement and availability.

\subsection{Reactive Production Planning}

The activities described in the beginning of sections 5.1 and 5.2 resulted in significant improvements in manufacturing lead-time and order lead-time. However these improvements have not enabled the company to adopt a Make-To-Order approach and although the volume of waste as a result of overproduction was reduced due to better manufacturing and supply chain activities there was still a need for a reactive production planning approach that can respond to the late changes in product demands. The final stage of the RDM Framework is based on the application of a two stage hybrid production planning approach, as outlined in figure 10.

[Insert figure 10 about here]

In this Two Stage Planning (TSP) approach, operations are divided into two categories of standard and special operations. Standard operations are those which do not give the product identity and are shared among many products. Special operations are those that give identity to a product. The main principle of the two stage planning is to use forecasts to plan for standard operations in the first stage to generate a soft schedule, and then to utilise a dynamic (real time) approach for the planning of special operations in the second stage, when orders are confirmed. The confirmed production levels will be used to re-adjust the batch sizes for special operations to produce a hard schedule for the final workplan based on confirmed orders. The PREACTOR software scheduling system (Preactor International 2002) was adopted in this case-study to implement the TSP model. PREACTOR is a highly configurable finite capacity planning system using graphical interfaces for ease of use and rapid access to information. The recent development in PREACTOR Advanced Planning System (APS) based upon Static Material Control (SMC) and Dynamic Material Control (DMC), enabled the implementation of the TSP model. A 
simple example of a soft and a hard schedule developed for a sub-set of orders in the casestudy company is depicted in Figure 11.

[Insert figure 11 about here]

In this example, the soft schedule contained a range of standard operations namely cleaning processes, preparation, cooking meat, etc. and the hard schedule mainly included the special operations in the assembly lines (e.g. adding sauces and packaging). The application of this hybrid planning approach enabled the company to significantly reduce their OPW through proactive consideration of common ingredient requirements and postponement of planning decisions for special operations until after order confirmation.

\section{Conclusions}

Minimisation of waste is one of the major objectives within 'Sustainable Production'. The waste as a result of overproduction presents a considerable source of waste in convenience food manufacture both in terms of cost and volumes of physical wastes generated. The underlying causes for creation of overproduction waste in food manufacture are mainly due to the inefficiencies in the supply chain relationship and the limited shelf life of products. This creates a production planning challenge that has traditionally been addressed by overproduction tactics.

The national and international legislation raising the profile of environmental considerations has led to the development of best practice guidelines and recommendations for waste management. These guidelines and recommendations are typically based on a 'reactive' approach for treatment and safe disposal of the various types of waste. The authors argue that the significant long term environmental benefits can only be obtained through a 'proactive' approach to waste minimisation by reconsidering the entire product life cycle including the production and supply chain systems. The research reported in this paper presents one such proactive approach targeted at convenience food manufacture through the application of a Responsive Demand Management framework, which aims to apply contemporary techniques for improvement of manufacturing and order lead-times in addition to the use of hybrid planning to reduce wastes resulting from overproduction. This is achieved by the 'postponement' of vital production planning decisions until after order confirmation.

The ever increasing consumer demand for a wider range of convenience food and onshelf product availability creates a challenging environment for manufacturers to produce a large variety of products to very short lead-times which could only be achieved through utilisation of reactive hybrid production planning approaches presented in this paper.

\section{Acknowledgements}

This research has been funded through the Wolfson School of Manufacturing and Mechanical Engineering at Loughborough University. The authors would like to acknowledge the contribution by their colleagues in the Centre for Sustainable Manufacturing And Reuse / Recycling Technologies (SMART).

\section{References}

Borri, F. and Boccaletti, G., 1995, From total quality management to total quality environmental management. The TQM Magazine, 7, 38-42. 
Darlington, R. and Rahimifard, S., 2004, Production responsive demand management within the food industry, in Proceedings of the International IFAC Conference on Manufacturing Modelling, Management and Control (IFAC_MIM'04), Athens, Greece, Paper \#32, [CD-ROM].

Directive 94/62/EC, 1995, Directive 94/62/EC of the European Parliament and of the council of 20 December 1994. Official Journal of the European Union, L 365 , 31/12/1994, 10 -23 .

Directive 04/12/EC of the European Parliament and of the council of 11 February 2004. Official Journal of the European Union, L 47, 18/2/2004, 26 - 31.

Directive 96/61/EC of the European Parliament and of the council of 24 September 1996. Official Journal of the European Union, L 257, 10/10/1996, 26 - 40.

Dorador, J. M. and Young, R.I.M., 2000, Application of IDEF0, IDEF3 and UML methodologies in the creation of information models. International Journal of Computer Integrated Manufacturing, 13, 430-445.

Environment Agency, 2001, Water Resources for the future, a strategy for England and Wales, (Bristol, UK: Environment Agency).

Fernie, J. and Hart, C., 2001, UK packaging waste legislation. British Food Journal, 103, 187-197.

Gupta, M., 1995, Environmental management and its impact on the operations function. International Journal of Operations and Production Management, 15, 34-51.

Hines, P. and Rich, N., 1997, The seven value stream mapping tools. International Journal of Operations \& Production Management, 17, 46-64.

Jones, D., Womack, J., 2002, Seeing the Whole, (Brookline, MA: The Lean Enterprise Institute).

Lillford, P. and Edwards, M., 1997, Clean technology in food processing. Physical Transactions: Mathematical, Physical and Engineering Sciences, 355, 1363-1371.

Maxwell, D. and van der Vorst, R., 2003, Developing sustainable products and services. Journal of Cleaner Production, 11, 883-895.

Pegg, A., 1999, Shelf-Life. Nutrition and food science, 99, 131-135.

Preactor International, 2002, PREACTOR User Manuals, (Chippenham, Wiltshire, UK: Preactor International)

Prendergast, G. and Pitt, L., 1996, Packaging, marketing, logistics and the environment: are there trade-offs? International Journal of Physical Distribution and Logistics Management, 26, 60-72. 
Sarkis, J., 2001, Manufacturing's role in corporate environmental sustainability. International Journal of Operations \& Production Management, 21, 666-686.

Simul8 corporation, 2001, Simul8 User Manuals, (Boston, USA: Simul8 Corporation).

Figure Captions

Figure 1, Waste Creation through life cycle of Convenience Food Supply

Figure 2, IDEF0 representation of the Waste Model for convenience food supply

Figure 3, An IDEF0 representation of Waste Model for Production Processes in Convenience Food Manufacture

Figure 4, Relationships between Manufacturing lead-time and Order lead-time for Food Industry Manufacture

Figure 5, Activities in RDM Framework for Waste Minimisation in convenience food manufacture

Figure 6, Value Stream Mapping (VSM) of case study product flows and communication channels

Figure 7, Improvement methods testing through Simulation Projects

Figure 8, Animation of Ready-meal materials handling improvement project built in SIMUL8

Figure 9, categorisation of tools and techniques for order lead-time improvement

Figure 10, Outline of the Two stage Planning Approach

Figure 11, Examples of Soft and Hard schedules in PREACTOR 


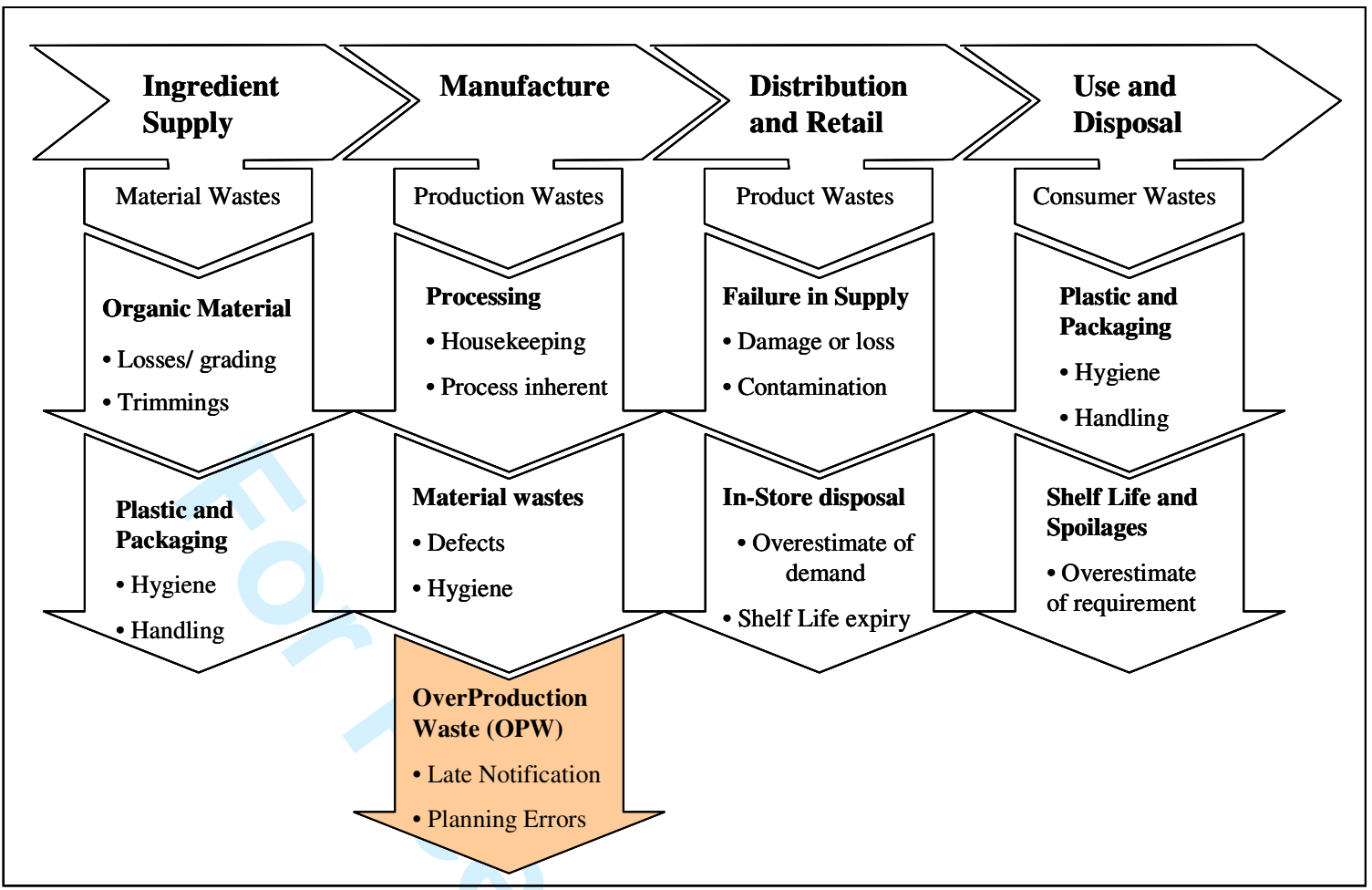




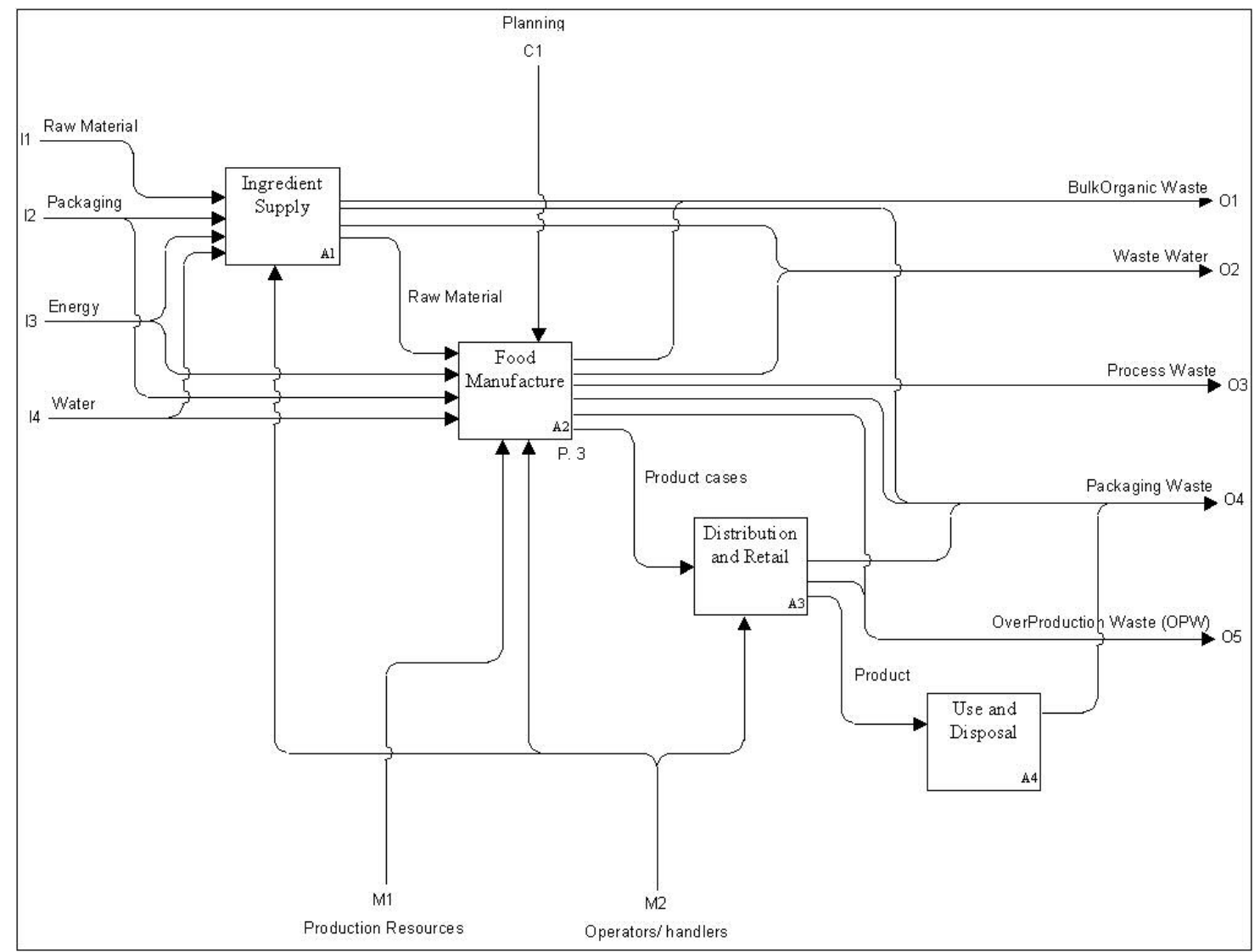




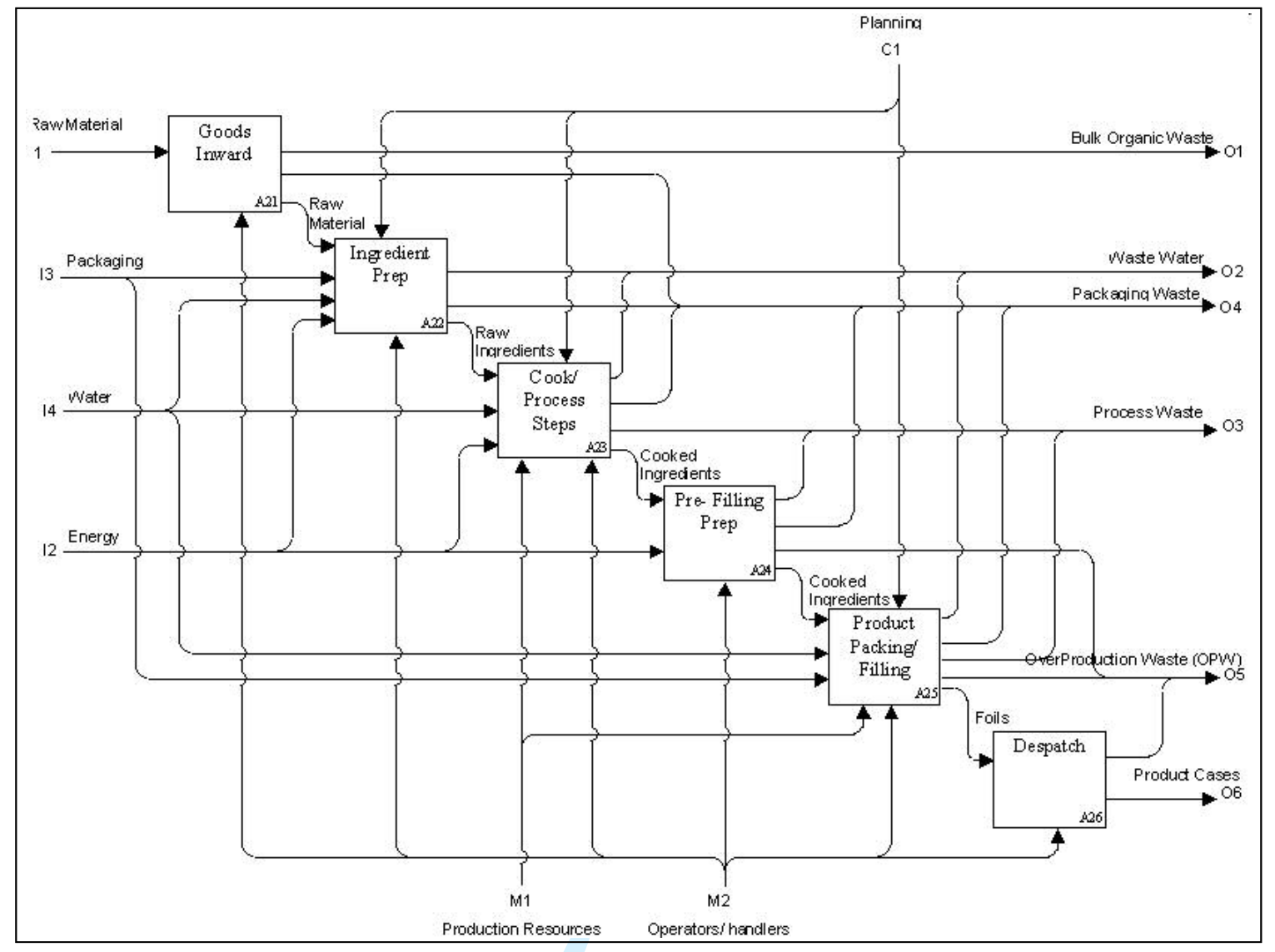


a) Representation of Make-To-Order manufacture

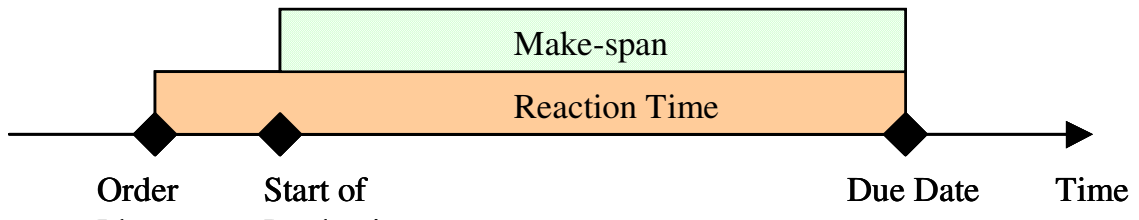

Placement Production

a) Representation of current manufacture of convenience foods

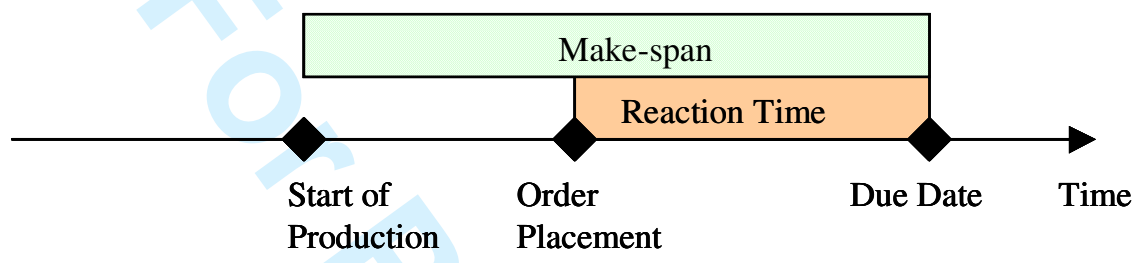

a) Research goal to minimise make-span and maximise Reaction Time

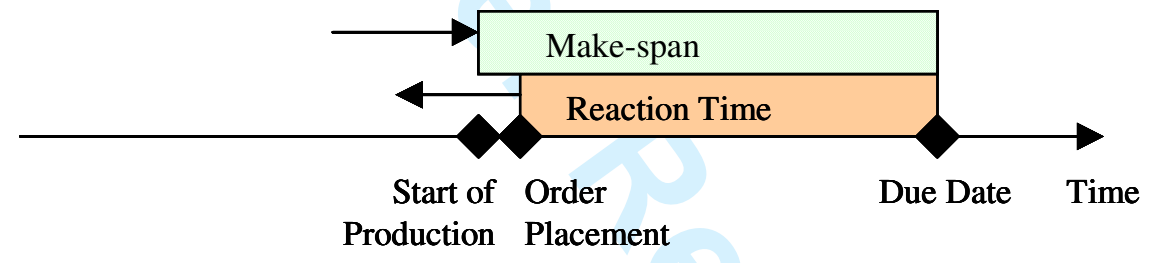




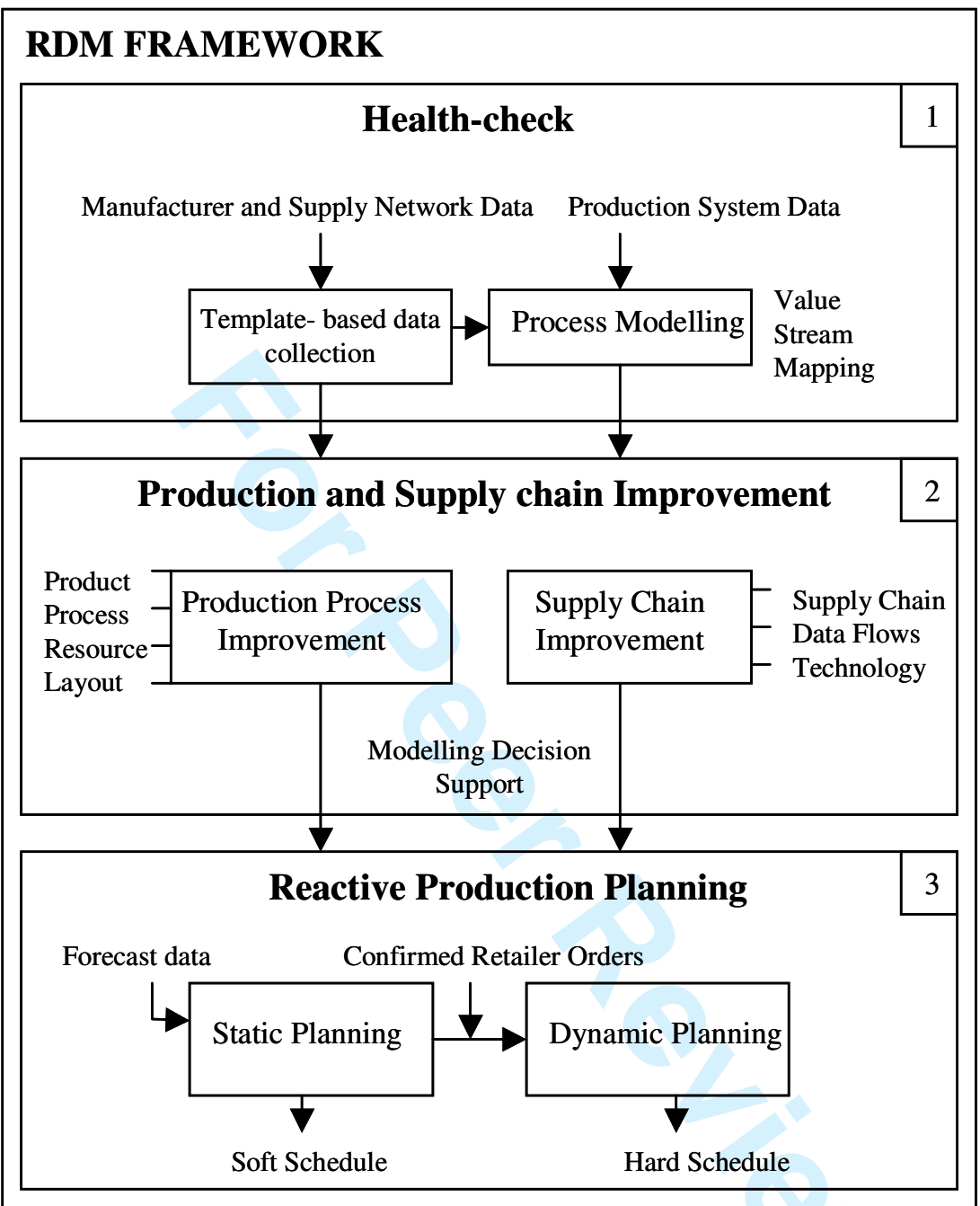




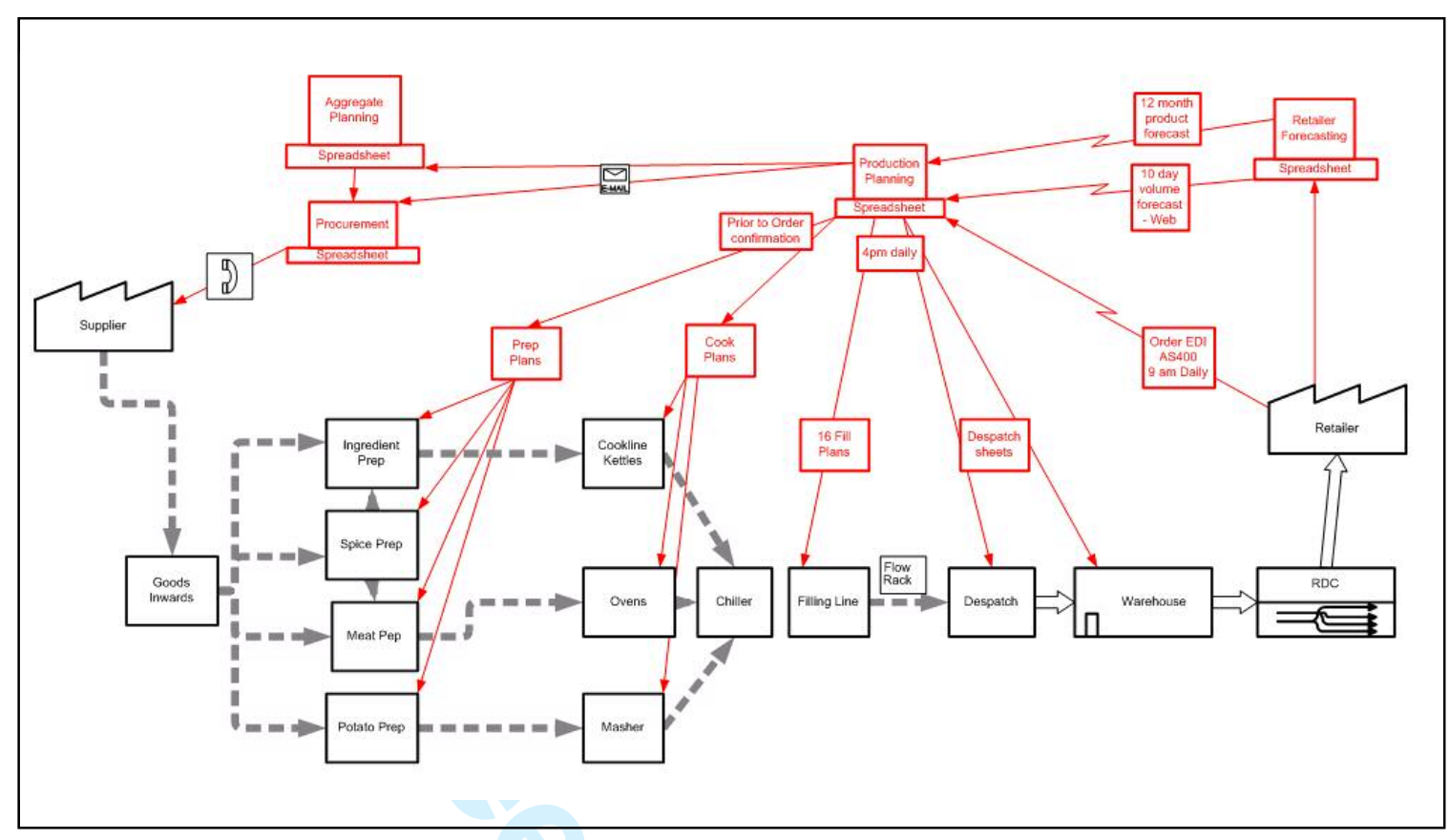




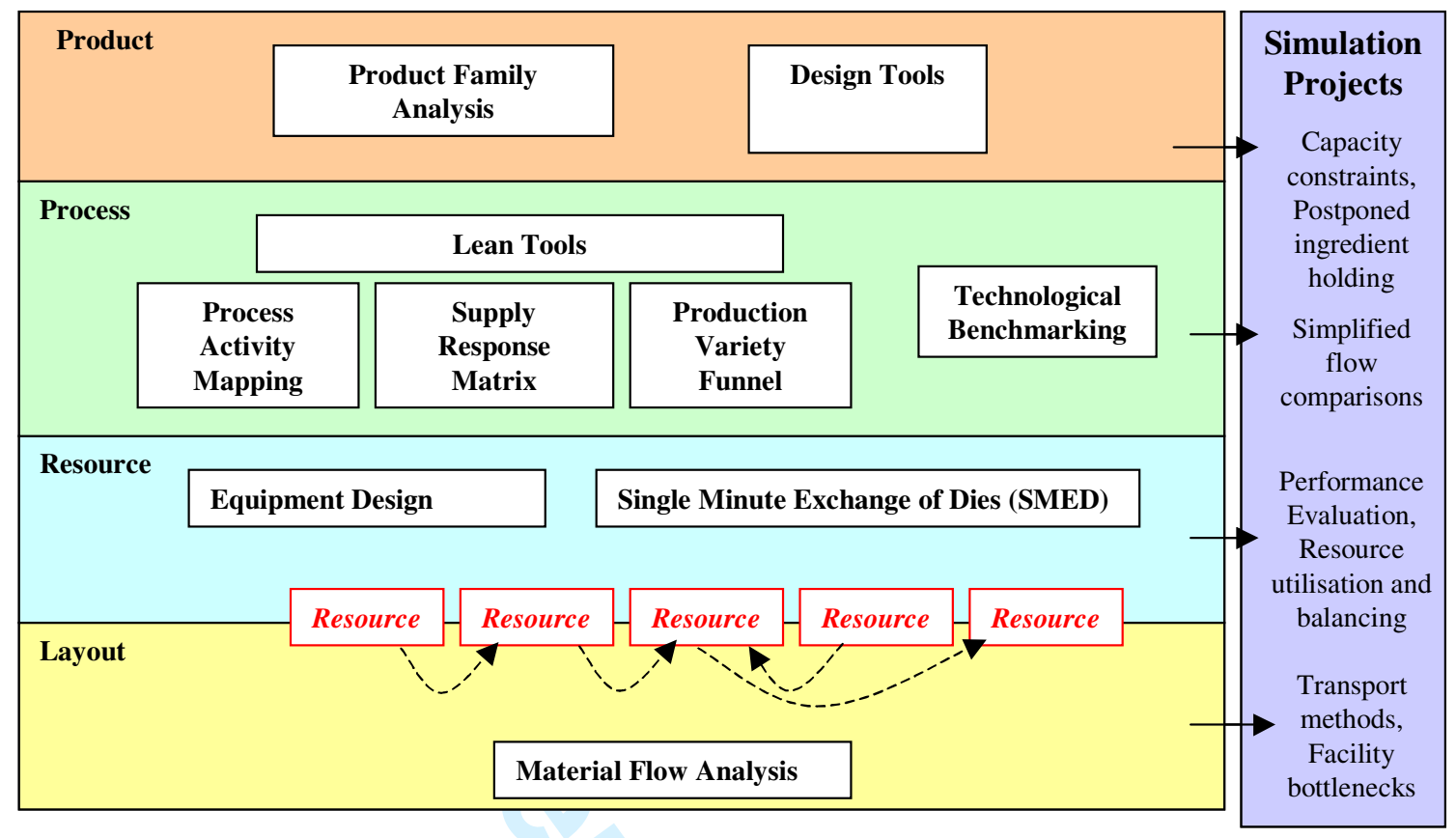




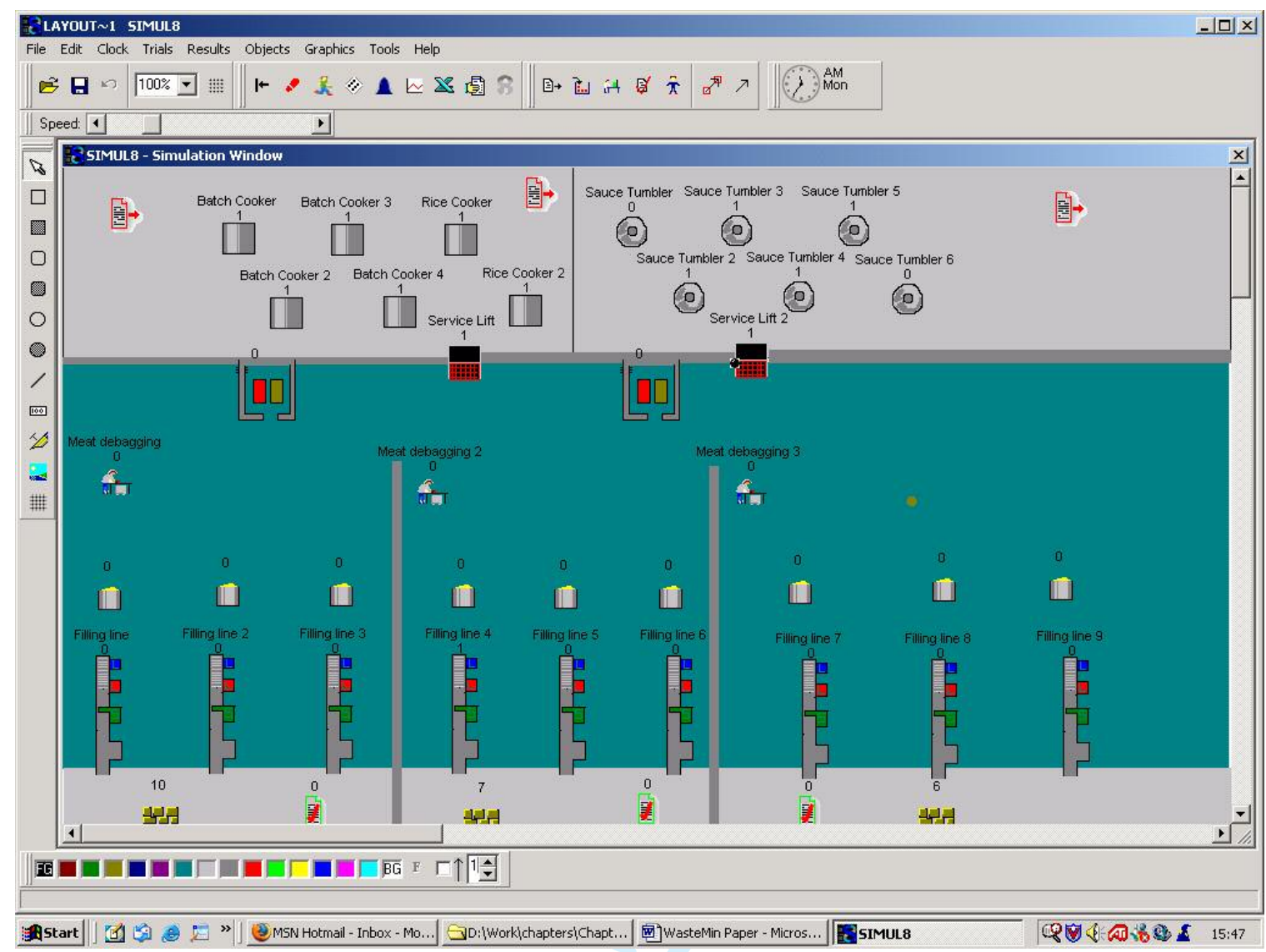




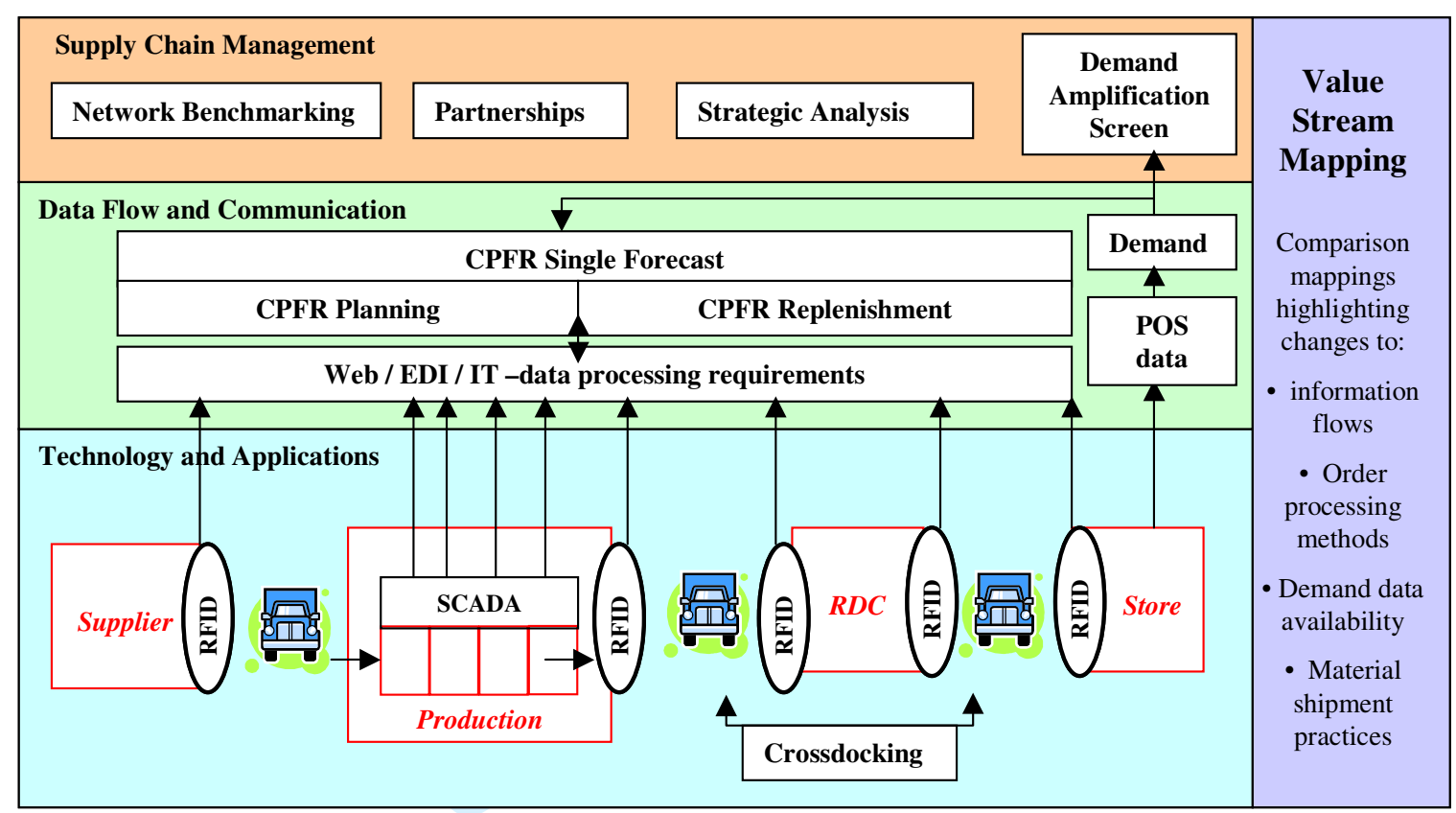




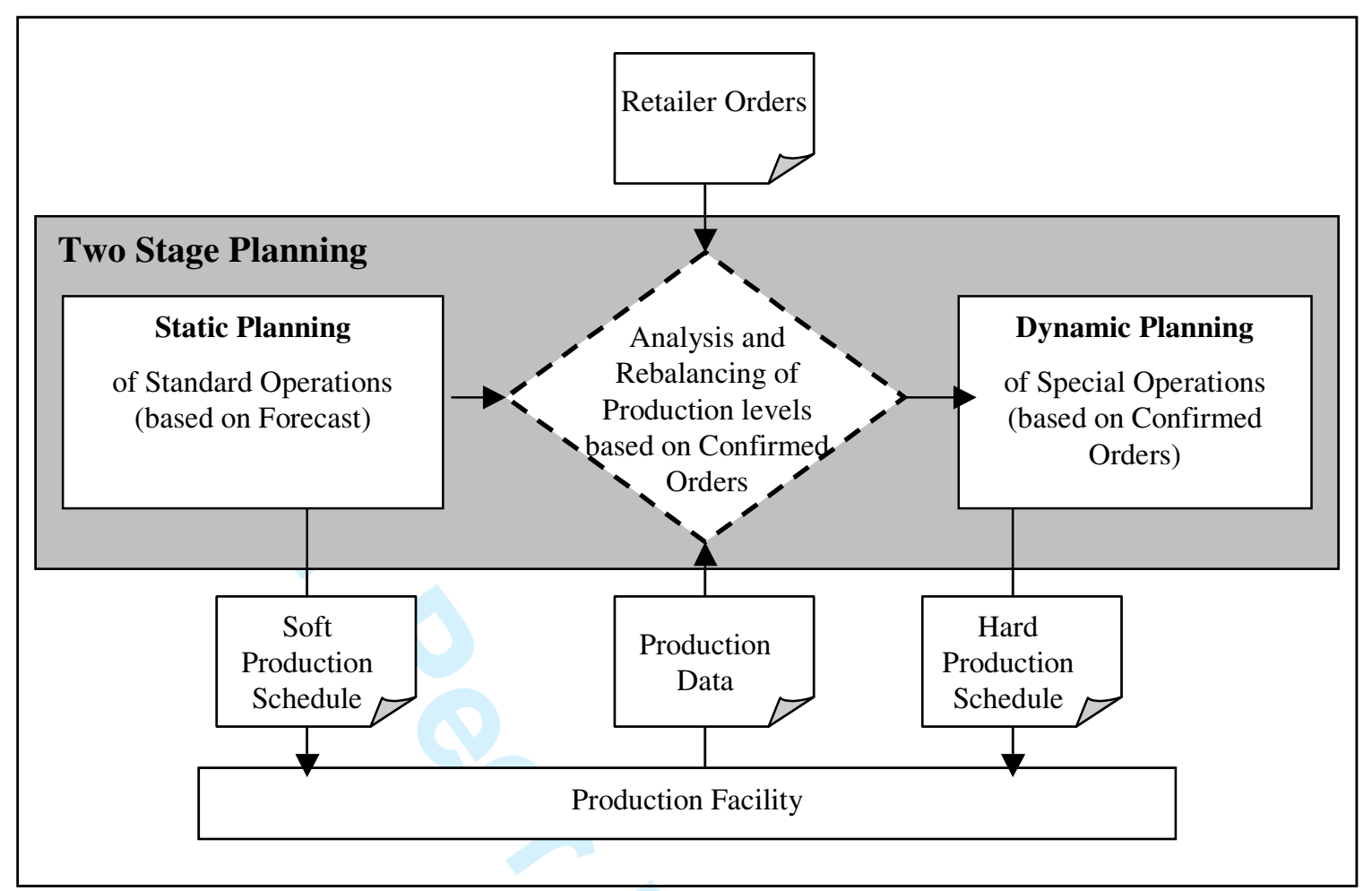




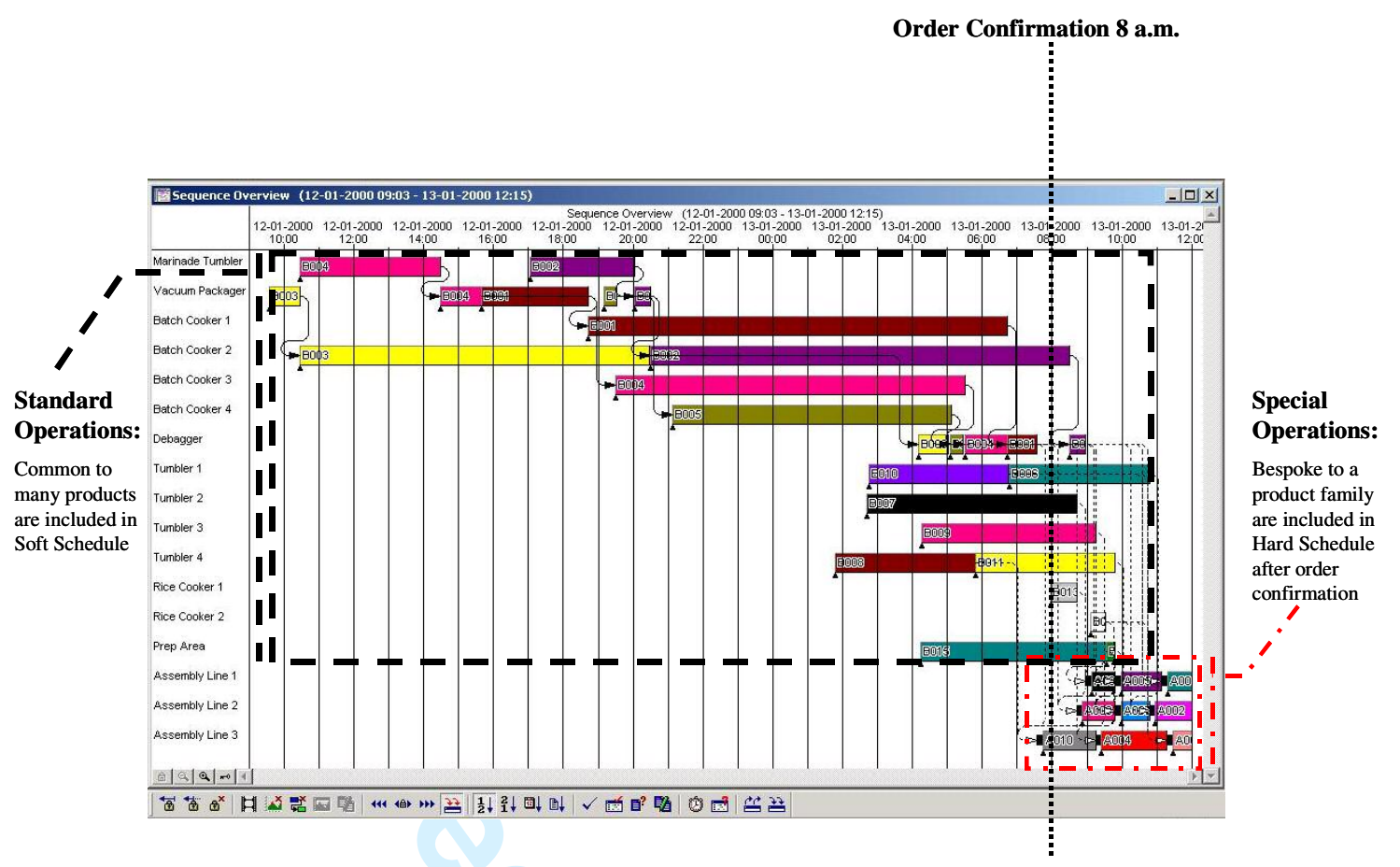

